\title{
Anthelmintic resistance among gastrointestinal nematodes of cattle on dairy calf to beef farms in Ireland
}

\author{
Anne C. Kelleher ${ }^{1,2}$, Barbara Good ${ }^{3}$, Theo de Waal $^{2}$ and Orla M. Keane ${ }^{1 *}$ (D)
}

\begin{abstract}
Background: The control of gastrointestinal nematodes (GIN) of cattle in pasture-based production systems such as Ireland is highly dependent on the availability of efficacious anthelmintics. There is very little information available on the efficacy of the broad-spectrum anthelmintics against GIN of cattle in Ireland and the aim of this study was to determine the prevalence of anthelmintic resistance on dairy calf to beef farms.

Results: GIN burden was monitored on thirty-six recruited farms by performing herd level faecal egg counts (FEC) every 2 weeks. Of these, nine farms were lost from the study as calves were treated with an anthelmintic for Dictyocaulus viviparus, two were lost as they treated for GIN, one dropped out of the study and on one the herd FEC did not reach the threshold for carrying out the Faecal Egg Count Reduction Test (FECRT). On the remaining 23 farms, once the herd FEC reached 100 eggs per gram, a FECRT was carried out. Pre and post-treatment larval cultures were also performed to identify the GIN to genus level. The efficacy of fenbendazole, levamisole, ivermectin and moxidectin was evaluated on 15,11,16 and 11 farms respectively. Resistance to fenbendazole was identified on 9 farms (60\%) with resistance suspected on a further farm. Resistance to levamisole, ivermectin and moxidectin was detected on 2 (18\%), 16 (100\%) and 8 (73\%) farms respectively. The predominant genera detected pre and post-treatment were Cooperia and Ostertagia with both genera detected post-treatment with fenbendazole and ivermectin. Due to the low proportion of Ostertagia spp. pre-treatment, the efficacy of levamisole or moxidectin against this genus could not be reliably established.
\end{abstract}

Conclusions: Anthelmintic resistance was widespread on the sampled dairy calf to beef farms in Ireland with resistance to benzimidazole, levamisole, ivermectin and moxidectin detected.

Keywords: Anthelmintic resistance, Gastrointestinal nematodes, Cattle, Cooperia, Ostertagia

\section{Background}

Irish beef production is predominately grass-based, with farmers aiming to have calves out to pasture as early as possible in the grazing season. However, an inevitable consequence of grazing is infection with nematode parasites, such as the gastrointestinal nematodes (GIN) Cooperia spp. and Ostertagia spp. and the lungworm

\footnotetext{
* Correspondence: orla.keane@teagasc.ie

'Animal \& Bioscience Department, Teagasc Grange, Dunsany, Co. Meath, Ireland

Full list of author information is available at the end of the article
}

Dictyocaulus viviparus [1, 2]. Calves in their first grazing season (FGS) are most at risk from these nematodes as they have not yet developed immunity $[3,4]$. Heavy infestations of these nematodes can cause substantial economic losses in young calves due to ill-thrift, in addition to morbidity and sometimes even mortality $[4,5]$. Anthelmintic treatments are often administered either prophylactically to prevent such losses or therapeutically to treat nematode infections [6]. The availability of efficacious anthelmintic products is therefore of great importance in Irish cattle rearing systems. 
There are currently three classes of broad-spectrum anthelmintics available for the control of GIN in cattle in Ireland, benzimidazoles (BZ), imidazothiazoles (LV) and macrocyclic lactones (ML). However, the chemoprophylactic approach to GIN control is threatened by the emergence of anthelmintic resistant nematode populations [7]. Anthelmintic resistance (AR) among GIN of small ruminants has previously been described [8-10] with widespread resistance reported in Ireland including populations of multi-drug resistant Teladorsagia circumcincta [11-13]. AR in GIN of cattle has been reported less frequently, although resistance has been identified in New Zealand, Australia, Europe and the USA [7, 14, 15]. While initial reports of inefficacy of these drugs identified the dose-limiting Cooperia spp. as the major species found post-treatment, inefficacy against Ostertagia spp. is increasingly reported [16-18]. Despite these reports, there is a dearth of knowledge regarding the extent of AR on Irish cattle farms. One study examined AR on 2 Irish beef research farms, enterprises with a large number of animal movements. On one farm fenbendazole, levamisole (LV) and ivermectin (IVM) were tested while on the second farm only IVM was tested. On both farms IVM resistant Cooperia spp. were identified [19]. A further study carried out on 4 dairy farms in the East of Ireland identified IVM resistant Cooperia spp. on each of them and resistant Ostertagia spp. on one farm [20]. Therefore, there is a need to quantify the extent of AR on cattle farms in Ireland. The aim of this study was to determine the efficacy of the three classes of anthelmintic drugs on commercial dairy calf to beef farms from Ireland.

\section{Methods}

\section{Recruitment of farms}

The study took place over the summers of 2017 and 2018. Farmers were recruited via the Teagasc drystock advisory service and interested farmers self-selected. In order to be considered for inclusion in the study, farmers required good animal handling facilities and to agree to submit calf faecal samples every 2 weeks until the faecal egg count reduction test (FECRT) was conducted. A minimum of 40 FGS calves was preferred. No attempt was made to ensure a systematic survey. Thirtysix dairy calf to beef farmers signed up for the study; 20 in 2017 and 16 in 2018. Four farms that participated in 2017 also participated in 2018 resulting in 20 farmers participating each year.

\section{Herd faecal egg count monitoring}

In order to monitor the herd faecal egg count (FEC), participating farmers were required to collect fresh field faecal samples from 10 to 15 FGS calves every 2 weeks from the 1st of May and submit the samples to Teagasc. Once the faecal samples were received, a composite sample was generated by pooling $5 \mathrm{~g}$ of faeces from each calf and mixing well. Nematode eggs in the composite faecal sample were enumerated using a modified miniFLOTAC method with a sensitivity of $5 \mathrm{epg}$. In brief, $5 \mathrm{~g}$ of the composite sample was suspended in $45 \mathrm{ml}$ of deionised water. Large debris was subsequently removed by passing the slurry solution through a $250 \mu \mathrm{m}$ sieve (Endecotts); the flow-through was then centrifuged at $433 \mathrm{~g}$ for $3 \mathrm{~min}$ and the pellet resuspended up to $50 \mathrm{ml}$ with saturated salt solution (specific gravity $=1.2$ ). The solution was inverted three times to mix and immediately used to fill 2 chambers of a mini-FLOTAC disk [21]. Eggs present in both chambers that were identified as Strongylid eggs were enumerated. The remainder of the composite faecal sample was examined for lungworm larvae using the Baermann technique [22]. If lungworm larvae were detected, the farmer was immediately contacted and advised of the result and invariably the calves were treated with an anthelmintic. The farm was then removed from the study to ensure the test was not performed on a pre-selected population of GIN. Herd faecal sample collection continued until the FECRT was carried out or the farm was removed from the study.

\section{Faecal egg count reduction test}

Once the herd FEC reached approximately 100 epg the farmer was contacted and a date arranged to visit the farm. A conservative 100 epg herd FEC threshold was chosen as it was considered sufficient to allow calculation of the egg count reduction after anthelmintic treatment but conservative enough that it would have been unlikely that some animals could have very high counts that could cause clinical disease in individual animals, which would have been unacceptable to the farmers. In 2017, BZ and IVM were tested and each farm was visited twice (days 0,14 ). On day 0 , up to 40 calves from the grazing group were selected and systematically allocated to one of two groups as they entered the crush. All calves were weighed using an electronic scale (Tru-Test) and individual faecal samples collected per rectum from each calf. One group of calves was treated with IVM (Ivomec, Merial Animal Health Ltd) subcutaneously at a rate of $0.2 \mathrm{mg} / \mathrm{kg}$ body weight. The second group of calves was treated with oral fenbendazole (Panacur, Intervet Ireland Ltd) at a rate of $7.5 \mathrm{mg} / \mathrm{kg}$ body weight. All anthelmintic delivery equipment was calibrated on the day of administration. The calves returned to pasture after treatment. Faecal samples were stored in $70 \mathrm{ml}$ faeces tubes (Starstedt) and transported to the laboratory where they were stored at $4{ }^{\circ} \mathrm{C}$ until analysis. On day 14 post-treatment the farm was revisited and faecal samples again collected from the calves per rectum. In 2018, LV and moxidectin (MOX) were tested and each farm was visited 3 times (days 0,7 and 14). On day 0 , up to 40 
calves from the grazing group were selected and systematically allocated to one of two groups as they entered the crush, all calves were weighted using an electronic scale and individual faecal samples collected per rectum from each calf. The first group received MOX (Cydectin, Zoetis Ireland Ltd) subcutaneously at a rate of $0.2 \mathrm{mg} / \mathrm{kg}$ body weight. The second group received oral LV (Levacide Low Volume Worm Drench, Norbrook Laboratories Limited) at a rate of $7.5 \mathrm{mg} / \mathrm{kg}$ body weight. All anthelmintic delivery equipment was calibrated on the day of administration. The calves returned to pasture after treatment. Individual calf faecal samples were collected per rectum from the calves that received LV on day 7 post-treatment while individual calf faecal samples were collected from calves that received MOX on day 14 post-treatment. On one farm in 2018 , all 4 anthelmintics were tested. The FECRT was conducted on calves that had not previously been treated with an anthelmintic product; however, on one farm (farm 10) the calves were treated with a BZ product prior to the start of the study; 4 months before the FECRT was conducted.

Individual calf faecal samples were analysed for GIN FEC using the mini-FLOTAC method as described above. Only animals with both a pre and post-FEC were included and animals with a pre-treatment FEC $<10$ epg were excluded from FECRT calculation. Groups with a mean pre-treatment FEC $<40$ epg were also excluded from further analysis due to the low FEC. Data were analysed using the Shiny web interface for the R package eggCounts with paired samples and allowing individual efficacy [23]. If the mean FEC increased after anthelmintic treatment, the default prior for modelling the reduction was changed to Uniform $(0,4)$ [23]. Resistance was considered present if the percentage reduction in egg count was $<95 \%$ and the lower value of the $95 \%$ uncertainty interval was $<90 \%$. If only one of these two criteria was met then resistance was suspected [24].

\section{Larval identification}

Larvae were cultured using standard techniques. Briefly, faeces were mixed with vermiculite and water and incubated at $23^{\circ} \mathrm{C}$ for 14 days with the culture mixed daily for the first 3 days and water added as needed. Thirdstage larvae were subsequently recovered by baermanisation [22]. A larval culture containing an equivalent mass of faeces from all animals with sufficient faecal material available was carried out for pre-treatment samples collected on day 0 , while coprocultures for each treatment group were carried out with faeces collected on day 7 or day 14. Larvae were stored in $175 \mathrm{ml}$ culture flasks with vented caps at $4{ }^{\circ} \mathrm{C}$ until larval identification. For each sample pre and post-treatment at least $100 \mathrm{~L} 3$ (or however many L3 were available if $<100$ ) were identified to genus level according to the diagrams and keys of van
Wyk and Mayhew [25]. The proportion of Cooperia spp. and Ostertagia spp. in each faecal culture was used to apportion the FEC pre and post anthelmintic treatment and to calculate the faecal egg count reduction (FECR) for each genus using a modified version of the RESO calculator, resoLootNew (https://wormmailinthecloud. wordpress.com/2011/03/25/drench-efficacy-calculatorsupdate/). A mean pre-treatment FEC of 20 epg was considered sufficient to calculate the FECR for each genus.

\section{Results \\ Participating farmers}

In total 36 farmers were recruited to the study; 20 farmers enrolled in 2017 while in 2018 a further 16 farmers enrolled while 4 farmers that had taken part in 2017 re-enrolled. However, the number of FECRTs completed was 15 in 2017 and 12 in 2018. In 2017, 4 farms were lost as calves were treated with an anthelmintic (2 treated for Dictyocaulus viviparus and 2 treated for GIN) and one farmer dropped out of the study. In 2018, 7 farms were lost as calves were treated with an anthelmintic (all were treated for Dictyocaulus viviparus) while on one farm the herd FEC did not exceed 20 epg and so the FECRT was not attempted. In total 3 tests were excluded as pre-treatment FEC did not reach the threshold of $40 \mathrm{epg}$. The number of tests completed and available for analysis for each anthelmintic is shown in Table 1.

\section{Faecal egg count reduction test}

The efficacy of BZ was evaluated on 15 farms; of these, BZ resistance was identified on 9 farms with FECRs ranging from 27 to $94 \%$ (Table 2). BZ was determined to be effective against GIN on 5 farms, while resistance was suspected on one farm (Farm 1; FECR $=96,95 \%$ U.I. $=86-100 \%$ ). LV efficacy was evaluated on 11 farms; resistant GIN were identified on 2 farms with FECRs of 83 and 92\% while GIN on the remaining 9 farms displayed LV susceptibility (Table 2). The efficacy of IVM and MOX was evaluated on 16 and 11 farms, respectively. Resistant GIN to IVM were confirmed on all 16 farms examined with FECRs ranging from - $181-93 \%$; in contrast resistance to MOX was identified on 8 farms (FECRs 34-94\%) with MOX susceptibility confirmed on 3 farms (Table 2).

\section{Larval identification}

Larvae were recovered from coprocultures pre and post anthelmintic treatment for 12 farms in 2017 with the exception of Farm 21 post-IVM treatment and for all farms in 2018 with the exception of Farm 14 post-MOX treatment. Cooperia and Ostertagia were the predominant genera present on all farms, although on four farms a small number of other genera were present pretreatment. Only Cooperia spp. or Ostertagia spp. were found post-treatment. The number of larvae, percentage 
Table 1 Number of farms that completed a faecal egg count reduction test (FECRT) with each anthelmintic class and the number available for analysis after data quality control

\begin{tabular}{lll}
\hline $\begin{array}{l}\text { No. farms enrolled } \\
\text { Benzimidazole }\end{array}$ & No. FECRT completed & $\begin{array}{l}\text { No. FECRT available } \\
\text { for analysis }\end{array}$ \\
21 & 16 & 15 \\
Levamisole & 12 & 11 \\
20 & 16 & 16 \\
Ivermectin & 16 & \\
21 & 12 & 11 \\
Moxidectin & & \\
20 & & \\
\hline
\end{tabular}

of Cooperia spp. and Ostertagia spp. identified pre and post-anthelmintic treatment and anthelmintic efficacy against Cooperia spp. and Ostertagia spp. are shown in Tables 3 (BZ and IVM) and 4 (LV and MOX).

\section{Discussion}

There are over 92,000 farms in Ireland, of which over 54,000 are classed as cattle rearing and fattening enterprises, which includes both dairy calf to beef and suckler beef production [26]. Despite the importance of this sector to the agricultural industry in Ireland, and the industry's reliance on a grass-based production system, there is a distinct lack of information on the prevalence of AR among GIN of cattle in Ireland, although resistance to IVM has been reported [19, 20]. This study provides clear evidence for resistance to all commonly available anthelmintic classes among GIN of cattle in Ireland,

Table 2 Number of animals, faecal egg count (FEC) pre and post treatment and FEC reduction (95\% uncertainty interval) for faecal egg count reduction tests (FECRT) carried out with benzimidazole, levamisole, ivermectin and moxidectin on dairy calf to beef farms in Ireland

\begin{tabular}{|c|c|c|c|c|c|c|c|c|c|c|c|c|c|c|c|c|}
\hline \multirow[t]{3}{*}{ Farm } & \multicolumn{4}{|c|}{ Benzimidazole (BZ) } & \multicolumn{4}{|c|}{ Levamisole (LV) } & \multicolumn{4}{|c|}{ Ivermectin (IVM) } & \multicolumn{4}{|c|}{ Moxidectin (MOX) } \\
\hline & \multirow[t]{2}{*}{$\begin{array}{l}\text { No. } \\
\text { calves }\end{array}$} & \multicolumn{2}{|c|}{$\begin{array}{l}\text { Mean } \\
\text { FEC (epg) }\end{array}$} & \multirow[t]{2}{*}{$\% F E C R(95 \%$ UI) } & \multirow[t]{2}{*}{$\begin{array}{l}\text { No. } \\
\text { calves }\end{array}$} & \multicolumn{2}{|c|}{$\begin{array}{l}\text { Mean } \\
\text { FEC (epg) }\end{array}$} & \multirow[t]{2}{*}{ \%FECR (95\% UI) } & \multirow[t]{2}{*}{$\begin{array}{l}\text { No. } \\
\text { calves }\end{array}$} & \multicolumn{2}{|c|}{$\begin{array}{l}\text { Mean } \\
\text { FEC (epg) }\end{array}$} & \multirow[t]{2}{*}{ \%FECR (95\% UI) } & \multirow[t]{2}{*}{$\begin{array}{l}\text { No. } \\
\text { calves }\end{array}$} & \multicolumn{2}{|c|}{$\begin{array}{l}\text { Mean } \\
\text { FEC (epg) }\end{array}$} & \multirow[t]{2}{*}{ \%FECR (95\% U } \\
\hline & & Pre & Post & & & Pre & Post & & & Pre & Post & & & Pre & Post & \\
\hline 1 & 16 & 139 & 6 & $96(86-100)$ & NT & NT & NT & NT & 18 & 140 & 49 & $65(47-78)$ & NT & NT & NT & NT \\
\hline 2 & 19 & 182 & 56 & $69(57-78)$ & 19 & 109 & 9 & $92(70-100)$ & 20 & 141 & 392 & $-181(-241--101)$ & 18 & 179 & 110 & $38(19-59)$ \\
\hline 3 & 19 & 341 & 25 & $93(89-95)$ & NT & NT & NT & NT & 20 & 380 & 162 & $58(43-69)$ & NT & NT & NT & NT \\
\hline 4 & NT & NT & NT & NT & 17 & 52 & 1 & $98(95-100)$ & NT & NT & NT & NT & 18 & 66 & 0 & $100(98-100)$ \\
\hline $5^{a}$ & 18 & 54 & 1 & 98 (94-99) & 20 & 48 & 1 & $99(96-100)$ & 19 & 56 & 6 & 89 (81-95) & 15 & 69 & 1 & $99(96-100)$ \\
\hline 6 & 15 & 287 & 17 & 94 (82-99) & NT & NT & NT & NT & 14 & 223 & 190 & $15(-78-74)$ & NT & NT & NT & NT \\
\hline 7 & 20 & 258 & 6 & $98(96-99)$ & NT & NT & NT & NT & 19 & 297 & 179 & $39(20-59)$ & NT & NT & NT & NT \\
\hline 8 & 20 & 217 & 71 & $68(55-77)$ & 18 & 409 & 1 & $100(100-100)$ & 19 & 205 & 58 & $72(59-80)$ & 19 & 317 & 37 & 88 (83-92) \\
\hline 9 & NT & NT & NT & NT & 18 & 266 & 0 & $100(100-100)$ & NT & NT & NT & NT & 18 & 144 & 54 & $62(37-84)$ \\
\hline 10 & 19 & 266 & 108 & $60(37-75)$ & NT & NT & NT & NT & 19 & 419 & 277 & $34(16-54)$ & NT & NT & NT & NT \\
\hline 11 & 13 & 118 & 85 & $27(12-50)$ & NT & NT & NT & NT & 14 & 82 & 6 & 93 (84-98) & NT & NT & NT & NT \\
\hline 12 & 17 & 132 & 14 & 89 (82-94) & NT & NT & NT & NT & 19 & 142 & 65 & $54(32-71)$ & NT & NT & NT & NT \\
\hline 13 & 18 & 165 & 18 & 89 (82-94) & NT & NT & NT & NT & 19 & 153 & 83 & $45(24-62)$ & NT & NT & NT & NT \\
\hline 14 & NT & NT & NT & NT & 18 & 67 & 0 & 100 (99-100) & NT & NT & NT & NT & 13 & 81 & 5 & 94 (89-98) \\
\hline 15 & NT & NT & NT & NT & $\mathrm{NC}$ & $\mathrm{NC}$ & $\mathrm{NC}$ & $N C$ & NT & NT & NT & NT & 17 & 48 & 2 & 97 (92-99) \\
\hline 16 & 18 & 572 & 21 & 96 (94-98) & NT & NT & NT & NT & 20 & 524 & 156 & $70(55-82)$ & NT & NT & NT & NT \\
\hline 17 & NT & NT & NT & NT & 16 & 129 & 3 & $98(95-100)$ & NT & NT & NT & NT & $\mathrm{NC}$ & $\mathrm{NC}$ & $\mathrm{NC}$ & $N C$ \\
\hline 18 & 19 & 177 & 2 & $99(98-100)$ & 18 & 72 & 12 & 83 (72-91) & 18 & 196 & 35 & $82(74-88)$ & 18 & 53 & 4 & 93 (86-98) \\
\hline 19 & NT & NT & NT & NT & 17 & 95 & 0 & $100(96-100)$ & NT & NT & NT & NT & 20 & 135 & 42 & $69(52-80)$ \\
\hline 20 & NT & NT & NT & NT & 18 & 118 & 1 & $99(97-100)$ & NT & NT & NT & NT & 19 & 97 & 7 & 93 (87-97) \\
\hline 21 & 20 & 152 & 1 & $99(98-100)$ & NT & NT & NT & NT & 18 & 110 & 35 & $69(50-82)$ & NT & NT & NT & NT \\
\hline 22 & $\mathrm{NC}$ & $\mathrm{NC}$ & $\mathrm{NC}$ & NC & NT & NT & NT & NT & 10 & 47 & 14 & $71(45-86)$ & NT & NT & NT & NT \\
\hline 23 & 19 & 76 & 8 & $90(84-95)$ & 19 & 45 & 0 & $100(98-100)$ & 20 & 77 & 33 & $57(34-74)$ & 17 & 43 & 28 & $34(17-62)$ \\
\hline
\end{tabular}

${ }^{\mathrm{a} F E C R T ~ w i t h ~ a l l ~} 4$ anthelmintic classes carried out in the same year. For all other farms, BZ and IVM were tested in 2017 and LV and MOX in 2018 $N C$ not calculated: pre-treatment FEC $<40$ epg

NT not tested: anthelmintic class not evaluated 
including resistance to IVM in Ostertagia spp. The study was carried out on dairy calf to beef farms throughout Ireland, although the majority were located in the Midlands, South and South East of the country where the dairy calf to beef industry is concentrated. The prevalence of anthelmintic treatment failure on sheep farms in Ireland does not depend on geographical region [12]; given the similar cattle production system throughout the country and large number of animal movements [27, 28], it is similarly expected that geographical region will have no impact on prevalence of AR on Irish cattle farms. The study farms had an average farm size of $48 \mathrm{ha}$, compared to the average for Irish cattle rearing farms of 31 ha and for other cattle farms excluding dairy (primarily cattle finishing enterprises) of 37 ha [26] indicating that these farms were larger than the average beef farming enterprise. Additionally, it must be noted that participating farmers self-selected; therefore these farmers may have been more interested in AR or may have perceived GIN control to be an issue on their farm. Therefore, these farms may not be truly representative of all dairy calf to beef farmers in Ireland. Notwithstanding this, other studies have confirmed that IVM resistance is common on cattle farms in Ireland, albeit few farms have been previously tested [19, 20]. Prior to this study, testing for AR had only occurred on one farm although some farmers reported that they perceived IVM had become less effective. Farm 5 had tested for and confirmed resistance to IVM 5 years prior to this study. Historically this farm treated all calves each year with ivermectin at 3,8 and 13 weeks post-turnout. In general, anthelmintic treatment practices varied both within farms from year to year and between farms and almost all treated with anthelmintics for Dictyocaulus.

A number of studies have demonstrated AR in GIN of cattle worldwide [29-32]. In particular, for IVM, resistance is commonly found in Cooperia spp., which is the dose-limiting species [18]. Ostertagia spp. have been reported present after treatment with IVM in only a few studies [17, 33, 34], suggesting resistance to ML is not common for this genus. In this study, IVM resistance was detected on all farms (100\%) tested. For all farms for which data was available, the reduction in the Cooperia-apportioned egg count after IVM treatment was < 95\% while the reduction in Ostertagia-apportioned egg count after IVM treatment was $<95 \%$ on 9 farms and $>$ $95 \%$ on 2 farms, indicating IVM resistance in both genera. On a number of farms, IVM failed to reduce the egg count apportioned to Cooperia at all. On one farm IVMresistant but MOX-susceptible GIN were identified, a situation reported previously $[13,15]$. MOX-resistance was also confirmed on 8/11 (73\%) of farms tested. Resistance among Cooperia spp. to MOX was also demonstrated; on all farms with confirmed MOX resistance, the reduction in Cooperia-apportioned egg count was $<95 \%$. Unfortunately the efficacy of MOX against Ostertagia spp. could not be tested due to the low abundance of Ostertagia in 2018.

BZ-resistance was also common, confirmed on 9/15 (60\%) farms tested with a further farm showing suspected resistance. The efficacy of BZ against both Ostertagia spp. and Cooperia spp. was $<95 \%$ on some farms, indicating $\mathrm{BZ}$ resistance in both genera in Ireland. The most efficacious class of anthelmintic was LV, only 2 farms (18\%) displayed LV resistance. On both of these

Table 3 Efficacy of benzimidazole (BZ) and ivermectin (IVM) against Cooperia spp. and Ostertagia spp. on Irish dairy calf to beef farms

\begin{tabular}{|c|c|c|c|c|c|c|c|c|c|}
\hline \multirow[t]{2}{*}{ Farm } & \multicolumn{3}{|c|}{ Pre-treatment } & \multicolumn{3}{|c|}{ Post-BZ treatment } & \multicolumn{3}{|c|}{ Post-IVM treatment } \\
\hline & No. L3 & $\%$ Cooperia & \%Ostertagia & No. L3 & $\begin{array}{l}\text { \%Cooperia } \\
\text { (\%efficacy) }\end{array}$ & $\begin{array}{l}\text { \%ostertagia } \\
\text { (\%efficacy) }\end{array}$ & No. L3 & $\begin{array}{l}\text { \%Cooperia } \\
\text { (\%efficacy) }\end{array}$ & $\begin{array}{l}\text { \%ostertagia } \\
\text { (\%efficacy) }\end{array}$ \\
\hline 2 & 100 & 67 & 33 & 100 & $3(99)$ & $97(11)$ & 100 & $76(0)$ & $24(0)$ \\
\hline 3 & 100 & 32 & 68 & 100 & $13(97)$ & $87(90)$ & 100 & $96(0)$ & $4(97)$ \\
\hline 5 & 100 & 41 & 59 & $\mathrm{~N} / \mathrm{A}$ & $\mathrm{N} / \mathrm{A}$ & $\mathrm{N} / \mathrm{A}$ & 100 & $96(68)$ & $4(99)$ \\
\hline 6 & 100 & 76 & 24 & 100 & $48(97)$ & $52(90)$ & 98 & $81(0)$ & $17(27)$ \\
\hline 7 & 100 & 4 & 96 & N/A & N/A & N/A & 100 & $33(0)^{a}$ & $67(54)$ \\
\hline 8 & 100 & 23 & 75 & 21 & $10(84)$ & $90(56)$ & 97 & $30(65)$ & $70(75)$ \\
\hline 10 & 35 & 57 & 43 & 100 & $41(63)$ & $59(30)$ & 100 & $54(7)$ & $46(40)$ \\
\hline 11 & 42 & 10 & 90 & 52 & $0(100)^{a}$ & $100(5)$ & 100 & $44(51)^{a}$ & $56(93)$ \\
\hline 12 & 100 & 16 & 84 & 24 & $0(100)$ & $24(87)$ & 100 & $32(0)$ & $68(58)$ \\
\hline 13 & 100 & 5 & 95 & 29 & $0(100)^{a}$ & $100(86)$ & 100 & $84(0)^{a}$ & $16(91)$ \\
\hline 16 & 100 & 72 & 27 & $\mathrm{~N} / \mathrm{A}$ & $\mathrm{N} / \mathrm{A}$ & $\mathrm{N} / \mathrm{A}$ & 100 & $90(51)$ & $10(85)$ \\
\hline 21 & 100 & 68 & 32 & N/A & N/A & N/A & - & - & - \\
\hline
\end{tabular}

N/A not applicable: treatment was considered effective

a Pre-treatment egg count apportioned to genus $<20$ epg

- no larvae recovered 
Table 4 Efficacy of levamisole (LV) and moxidectin (MOX) against Cooperia spp. and Ostertagia spp. on Irish dairy calf to beef farms

\begin{tabular}{|c|c|c|c|c|c|c|c|c|c|}
\hline \multirow[t]{2}{*}{ Farm } & \multicolumn{3}{|c|}{ Pre-treatment } & \multicolumn{3}{|c|}{ Post-LV treatment } & \multicolumn{3}{|c|}{ Post-MOX treatment } \\
\hline & No. L3 & \%Cooperia & \%Ostertagia & No. L3 & $\begin{array}{l}\text { \%Cooperia } \\
\text { (\%efficacy) }\end{array}$ & $\begin{array}{l}\text { \%Ostertagia } \\
\text { (\%efficacy) }\end{array}$ & No. L3 & $\begin{array}{l}\text { \%Cooperia } \\
\text { (\%efficacy) }\end{array}$ & $\begin{array}{l}\text { \%Ostertagia } \\
\text { (\%efficacy) }\end{array}$ \\
\hline 2 & 100 & 100 & 0 & 100 & $67(87)$ & $33(0)^{\mathrm{a}}$ & 100 & $95(46)$ & $5(0)^{a}$ \\
\hline 4 & 100 & 76 & 24 & N/A & N/A & N/A & N/A & N/A & N/A \\
\hline 5 & 100 & 41 & 59 & N/A & N/A & $\mathrm{N} / \mathrm{A}$ & N/A & N/A & N/A \\
\hline 8 & 100 & 95 & 3 & N/A & N/A & N/A & 100 & $99(86)$ & $1(96)^{a}$ \\
\hline 9 & 100 & 99 & 1 & N/A & N/A & N/A & 100 & $100(48)$ & $0(100)^{a}$ \\
\hline 14 & 100 & 87 & 13 & N/A & N/A & N/A & - & - & - \\
\hline 15 & 100 & 22 & 87 & NC & NC & NC & $\mathrm{N} / \mathrm{A}$ & N/A & $\mathrm{N} / \mathrm{A}$ \\
\hline 17 & 100 & 78 & 22 & N/A & N/A & N/A & NC & NC & NC \\
\hline 18 & 100 & 97 & 3 & 100 & $91(80)$ & $9(37)^{a}$ & 100 & $100(92)$ & $0(100)^{a}$ \\
\hline 19 & 66 & 100 & 0 & N/A & N/A & $\mathrm{N} / \mathrm{A}$ & 100 & $100(67)$ & $0(N D)^{a}$ \\
\hline 20 & 100 & 95 & 5 & N/A & N/A & N/A & 100 & $100(92)$ & $0(100)^{\mathrm{a}}$ \\
\hline 23 & 100 & 100 & 0 & N/A & N/A & N/A & 100 & $100(5)$ & $0(N D)^{a}$ \\
\hline
\end{tabular}

N/A not applicable: treatment was considered effective

NC not calculated: pre-treatment FEC $<40$ epg

ND not determined: efficacy could not be determined as the genus was not detected pre-treatment

- no larvae recovered

a Pre-treatment egg count apportioned to genus $<20$ epg

farms efficacy against Cooperia spp. was < 95\%; however efficacy against Ostertagia spp. could not be tested due to the low abundance of this genus. Generally Cooperia spp. are considered less pathogenic than Ostertagia spp. and calves are expected to develop immunity to Cooperia spp. reasonably quickly [35]. The detection of both $\mathrm{ML}$ and BZ-resistant Ostertagia spp. in Ireland is a particular cause for concern. LV has been reported to have poor efficacy against all stages of $O$. ostertagia [36] and $\mathrm{BZ}$ and ML anthelmintics are the most commonly recommended classes to use for the prevention of type II ostertagiosis due to their efficacy against both mature and immature nematodes [37].

The study was carried out in 2017 and 2018 but weather conditions for GIN transmission were more favourable in 2017. A drought in the summer of 2018 [38] meant that most farms presented with low herd FEC until at least mid-July. This was likely due to the lack of moisture, making it difficult for larvae to migrate out of the faecal pats combined with exposure of L3 to UV irradiation [39]. Therefore, mean FEC pre-treatment was generally higher in 2017 than in 2018. Notably, the 2018 weather conditions may also have differentially impacted Ostertagia spp. compared to Cooperia spp. as the proportion of Ostertagia spp. recovered from larval cultures was very low in 2018. This fact, combined with the lower pre-treatment FEC, meant that the proportion of FEC that could be apportioned to Ostertagia was too low to reliably test anthelmintic efficacy against this genus in 2018. However, it must be noted that many factors such as egg-laying capacity, immunity or density-dependent suppression of egg laying as well as the culture conditions, which may not be optimal for all species, can all have an effect on the recovery rate of the different GIN species. Therefore, the species-specific values determined from larval cultures may not necessarily fully reflect the true species-specific egg counts or the worm burden in vivo [40-42].

Putative infection with $D$. viviparus was another factor which limited the number of farms included in the study. The high prevalence of this nematode in Ireland [43] combined with the unpredictable nature and severe consequences of the disease in naïve calves means that farmers monitor calves closely and commonly treat with an anthelmintic at signs of respiratory disease [44]. In this study, $25 \%$ of participating farmers were excluded as calves were treated with an anthelmintic before herd FEC reached the 100 epg threshold required to carry out the FECRT. While a vaccine for Dictyocaulus is available in Ireland, uptake is low (MSD Ireland, pers. comm.) and the recommendation to house calves until at least 14 weeks of age is not compatible with optimising the contribution of grazed grass to feed intake [45]. A modified vaccine schedule in which calves were vaccinated at 6 and 8 weeks of age and turned out to pasture immediately after the second vaccination showed efficacy under delayed Dictyocaulus challenge; however, it was not as effective as the conventional vaccine schedule during severe pasture challenge [46]. The heavy reliance on anthelmintic drugs, particularly MLs, to control and treat Dictyocaulus infection may be a contributing factor in the rise of AR in GIN. 
The use of an untreated control group is generally recommended for FECRT, in order to allow for natural changes in FEC during the test $[47,48]$. In this instance, a control group was not utilised due to farmer's perceptions of the risk from GIN and Dictyocaulus in an untreated group. However, the "eggCounts" package allowing individual efficacy was utilised along with the mini-FLOTAC method which has a sensitivity of 5 epg. Utilising an egg counting technique with high sensitivity has been reported to give good precision in the detection of AR [49]. It is also recommended for cattle that only oral formulations should be used in a FECRT [47]. Indeed it has been reported that oral MOX treatments are significantly less variable and more effective than injectable or pour-on treatments [50]. However, there is no oral IVM or MOX available on the market for cattle in Ireland.

The level of AR identified in this study demonstrates that strategies to manage GIN in the face of AR are urgently needed on Irish cattle farms. There is a dearth of information on parasite control practices on Irish cattle rearing and fattening farms and these need to be examined in order to identify risk factors associated with the development of AR and to take steps to mitigate these risks. Promoting the use of sustainable parasite control strategies is now imperative. Effective anthelmintic administration should be immediately promoted including appropriate anthelmintic selection, treating to the weight of the heaviest animal, calibration of anthelmintic administration equipment and good anthelmintic administration technique [51]. Strategies to increase refugia such as evaluating the need to treat older animals and grazing management, including avoiding moving stock to lowly contaminated pasture after treatment, should also be adopted. Indicators such as FEC or weight gain should be utilised to help target anthelmintic treatments [52]. In addition, further research on novel strategies for managing AR GIN or slowing the further development of AR, such as combination therapy or targeted selective treatment, is required. However, $43 \%$ of cattle rearing enterprises in Ireland are considered to be economically vulnerable, with the farm business not viable and no offfarm income [26]. Therefore strategies need to be developed that are appropriate to the needs and resources of Irish beef farmers.

\section{Conclusion}

Irish cattle rearing relies on a pasture-based production system, aiming to maximise the contribution of grazed grass in the animal's diet [28]. Effective nematode control is critical in this system and to-date such control has been dependent on the availability of efficacious anthelmintics. The high prevalence of anthelmintic resistance found by this study indicates that anthelmintic resistance is a threat to our grass-based production system. Sustainable worm control strategies, such as grassland management and targeted treatments, which prolong the life span of the currently available anthelmintics need to be implemented as a matter of urgency. However, as the emphasis in GIN control shifts from that of chemoprophylaxis, the impact on infection with Dictyocaulus will also need to be considered.

\section{Abbreviations}

AR: Anthelmintic resistance; BZ: Benzimidazoles; FEC: Faecal Egg Count; FECR: Faecal egg count reduction; FECRT: Faecal Egg Count Reduction Test; FGS: First grazing season; GIN: Gastrointestinal nematode; IVM: Ivermectin; LV: Levamisole; ML: Macrocyclic lactone; MOX: moxidectin

\section{Acknowledgements}

The authors gratefully acknowledge the contribution of all farmers who participated in the study. We thank Pearse Kelly and the Teagasc drystock advisors for aiding with farmer recruitment. We also thank Teagasc staff, particularly Francis Collier, Joe Gill, Peter Grimes, Edward Mulligan, Martin Ryan, Pat Kane, Tony Curry and John Horan for their support and assistance with the farm visits and sample collection. We gratefully appreciate the assistance of Padraig O'Boyle, Shawnaa Desmond and David O'Keeffe with egg counting. Many thanks also to James O'Shaughnessy (DAFM) for assistance with larval identification.

\section{Authors' contributions}

BG, TDW and OMK designed the experiments. ACK performed sample collection and analysis. ACK, TDW and OMK analysed the data and prepared the manuscript. The author(s) read and approved the final manuscript.

\section{Funding}

The research was funded by a Walsh Fellowship award GEAB0033.

\section{Availability of data and materials}

The datasets analysed during the current study are available from the corresponding author on reasonable request.

Ethics approval and consent to participate

All procedures involving animals were conducted with the approval of the Teagasc Animal Ethics Committee. Owner consent was also obtained for all animal sampling.

\section{Consent for publication}

Not applicable.

\section{Competing interests}

The author's declare they have no competing interests.

\section{Author details}

${ }^{1}$ Animal \& Bioscience Department, Teagasc Grange, Dunsany, Co. Meath, Ireland. ${ }^{2}$ School of Veterinary Medicine, University College Dublin, Belfield, Dublin 4, Ireland. ${ }^{3}$ Animal \& Bioscience Department, Teagasc Mellows Campus, Athenry, Co. Galway, Ireland.

Received: 6 January 2020 Accepted: 26 June 2020 Published online: 01 July 2020

\section{References}

1. O'Shaughnessy J, Earley B, Mee JF, Doherty ML, Crosson P, Barrett D, de Waal T. Nematode control in suckler beef cattle over their first two grazing seasons using a targeted selective treatment approach. Ir Vet J. 2015;68(1):13

2. Murphy TM, Fahy KN, McAuliffe A, Forbes AB, Clegg TA, O'Brien DJ. A study of helminth parasites in culled cows from Ireland. Prev Vet Med. 2006;76(12):1-10.

3. Eysker M, Boersema JH, Kooyman FN, Ploeger HW. Resilience of second year grazing cattle to parasitic gastroenteritis following negligible to moderate exposure to gastrointestinal nematode infections in their first year. Vet Parasitol. 2000;89(1-2):37-50.

4. David G. Strategies for the control of parasitic bronchitis in cattle. In Practice. 1999;21:62-8. 
5. Shaw DJ, Vercruysse J, Claerebout E, Dorny P. Gastrointestinal nematode infections of first-grazing season calves in Western Europe: general patterns and the effect of chemoprophylaxis. Vet Parasitol. 1998;75(2-3):115-31.

6. Bloemhoff Y, Danaher M, Andrew F, Morgan E, Mulcahy G, Power C, Sayers R. Parasite control practices on pasture-based dairy farms in the Republic of Ireland. Vet Parasitol. 2014;204(3-4):352-63.

7. Rose H, Rinaldi L, Bosco A, Mavrot F, de Waal T, Skuce P, Charlier J, Torgerson PR, Hertzberg H, Hendrickx G, et al. Widespread anthelmintic resistance in European farmed ruminants: a systematic review. Vet Rec. 2015;176(21):546.

8. Good B, Hanrahan JP, de Waal DT, Patten T, Kinsella A, Lynch CO. Anthelmintic-resistant nematodes in Irish commercial sheep flocks- the state of play. Ir Vet J. 2012;65(1):21.

9. Kaplan RM. Drug resistance in nematodes of veterinary importance: a status report. Trends Parasitol. 2004;20(10):477-81.

10. Papadopoulos E, Gallidis E, Ptochos S. Anthelmintic resistance in sheep in Europe: a selected review. Vet Parasitol. 2012;189(1):85-8.

11. Keane OM, Keegan JD, Good B, De Waal T, Fanning J, Gottstein M, Casey M, Hurley C, Sheehan M. High level of treatment failure with commonly used anthelmintics on Irish sheep farms. Ir Vet J. 2014;67(1):16.

12. Keegan JD, Keane OM, Good B, De Waal T, Denny M, Hanrahan JP, Fitzgerald W, Sheehan M. A nationwide survey of anthelmintic treatment failure on sheep farms in Ireland. Ir Vet J. 2017;70:7.

13. Keegan JD, Keane OM, Farrell L, Byrne W, de Waal T, Good B. Characterisation of ivermectin and multi-drug resistance in two field isolates of Teladorsagia circumcincta from Irish sheep flocks. Vet Parasitol Reg Stud Reports. 2015;1-2:3-9.

14. Cotter JL, Van Burgel A, Besier RB. Anthelmintic resistance in nematodes of beef cattle in south-West Western Australia. Vet Parasitol. 2015;207(3-4):276-84.

15. Edmonds MD, Johnson EG, Edmonds JD. Anthelmintic resistance of Ostertagia ostertagi and Cooperia oncophora to macrocyclic lactones in cattle from the western United States. Vet Parasitol. 2010;170(3-4):224-9.

16. Coles GC, Watson CL, Anziani OS. Ivermectin-resistant Cooperia in cattle. Vet Rec. 2001;148(9):283-4.

17. Waghorn TS, Miller CM, Leathwick DM. Confirmation of ivermectin resistance in Ostertagia ostertagi in cattle in New Zealand. Vet Parasitol. 2016;229:139-43.

18. Geurden T, Chartier C, Fanke J, di Regalbono AF, Traversa D, von SamsonHimmelstjerna G, Demeler J, Vanimisetti HB, Bartram DJ, Denwood MJ. Anthelmintic resistance to ivermectin and moxidectin in gastrointestinal nematodes of cattle in Europe. Int J Parasitol Drugs Drug Resist. 2015;5(3):163-71.

19. O'Shaughnessy J, Earley B, Mee JF, Doherty ML, Crosson P, Barrett D, Prendiville $R$, Macrelli $M$, de Waal T. Detection of anthelmintic resistance on two Irish beef research farms. Vet Rec. 2014;175(5):120.

20. O'Shaughnessy J, Drought Y, Lynch J, Denny M, Hurley C, Byrne W, Casey M, de Waal T, Sheehan M. Ivermectin treatment failure on four Irish dairy farms. Ir Vet J. 2019;72:4

21. Bosco A, Rinaldi L, Maurelli MP, Musella V, Coles GC, Cringoli G. The comparison of FLOTAC, FECPAK and McMaster techniques for nematode egg counts in cattle. Acta Parasitol. 2014;59(4):625-8.

22. MAFF: Manual of Veterinary Parasitology Laboratory Techniques. Reference Book 418., 3rd edn: Ministry of Agriculture, Fisheries and Food. 3rd edition HMSO; 1986.

23. Wang C, Torgerson PR, Kaplan RM, George MM, Furrer R. Modelling anthelmintic resistance by extending eggCounts package to allow individual efficacy. Int J Parasitol Drugs Drug Resist. 2018;8(3):386-93.

24. Coles GC, Bauer C, Borgsteede FH, Geerts S, Klei TR, Taylor MA, Waller PJ. World Association for the Advancement of veterinary parasitology (W.a.a.V.P. ) methods for the detection of anthelmintic resistance in nematodes of veterinary importance. Vet Parasitol. 1992;44(1-2):35-44.

25. van Wyk JA, Mayhew E. Morphological identification of parasitic nematode infective larvae of small ruminants and cattle: a practical lab guide. Onderstepoort J Vet Res. 2013;80(1):539.

26. Dillon EJ, Moran B, Lennon J, Donnellan T. Teagasc National Farm Survey 2018 results. In: Teagasc; 2019. p. 1-95.

27. McGrath G, Tratalos JA, More SJ. A visual representation of cattle movement in Ireland during 2016. Ir Vet J. 2018;71:18.

28. Teagasc: Beef production system guidelines. 2015.

29. Bartley DJ, McArthur CL, Devin LM, Sutra JF, Morrison AA, Lespine A, Matthews JB. Characterisation of macrocyclic lactone resistance in two fieldderived isolates of Cooperia oncophora. Vet Parasitol. 2012;190(3-4):454-60.
30. Sutherland IA, Leathwick DM. Anthelmintic resistance in nematode parasites of cattle: a global issue? Trends Parasitol. 2011;27(4):176-81.

31. Stafford K, Coles GC. Nematode control practices and anthelmintic resistance in dairy calves in the south west of England. Vet Rec. 1999; 144(24):659-61.

32. Anziani OS, Suarez V, Guglielmone AA, Warnke O, Grande H, Coles GC. Resistance to benzimidazole and macrocyclic lactone anthelmintics in cattle nematodes in Argentina. Vet Parasitol. 2004;122(4):303-6.

33. Demeler J, Van Zeveren AM, Kleinschmidt N, Vercruysse J, Hoglund J, Koopmann R, Cabaret J, Claerebout E, Areskog M, von SamsonHimmelstjerna G. Monitoring the efficacy of ivermectin and albendazole against gastrointestinal nematodes of cattle in northern Europe. Vet Parasitol. 2009;160(1-2):109-15.

34. Rendell DK. Anthelmintic resistance in cattle nematodes on 13 south-west Victorian properties. Aust Vet J. 2010:88(12):504-9.

35. Candy PM, Waghorn TS, Miller CM, Ganesh S, Leathwick DM. The effect on liveweight gain of using anthelmintics with incomplete efficacy against resistant Cooperia oncophora in cattle. Vet Parasitol. 2018;251:56-62.

36. Williams JC, Knox JW, Marbury KS, Swalley RA, Eddi CS. Efficacy of levamisole against Ostertagia ostertagi in Louisiana cattle during maturation of inhibited larvae (September) and during minimal inhibition (December/ January). Vet Parasitol. 1991;40(1-2):73-85.

37. Myers GH, Taylor RF. Ostertagiasis in cattle. J Vet Diagn Investig. 1989; (2):195-200.

38. Climate statement for 2018. https://www.met.ie/climate-statements-for-201 8-and-december-2018. Accessed 16 Dec 2019.

39. Morgan ER, van Dijk J. Climate and the epidemiology of gastrointestinal nematode infections of sheep in Europe. Vet Parasitol. 2012;189(1):8-14.

40. Berrie DA, East IJ, Bourne AS, Bremner KC. Differential recoveries from faecal cultures of larvae of some gastro-intestinal nematodes of cattle. J Helminthol. 1988;62(2):110-4.

41. Bryan RP, Kerr JD. The relation between the natural worm burden of steers and the faecal egg count differentiated to species. Vet Parasitol. 1989;30(4):327-34.

42. Brunsdon RV. Trichostrongyle worm infection in cattle: ostertagiasis--effect of a field outbreak on production, with a review of the disease syndromes, problems of diagnosis and treatment. N Z Vet J. 1968;16(12):176-87.

43. Bloemhoff Y, Forbes A, Good B, Morgan E, Mulcahy G, Strube C, Sayers R. Prevalence and seasonality of bulk milk antibodies against Dictyocaulus viviparus and Ostertagia ostertagi in Irish pasture-based dairy herds. Vet Parasitol. 2015;209(1-2):108-16.

44. Kelleher AC. Resistance to anthelmintics among gastrointestinal nematode populations in dairy calf to beef farms in Ireland. MSc. Dublin: University College Dublin; 2019.

45. Ashfield A, Wallace M, Prendiville R, Crossan P. Bioeconomic modelling of male Holstein-Friesian dairy calf-to-beef production systems on Irish farms. Ir J Agric Food Res. 2014;53(2):133-47.

46. Downey NE. Evaluation of a modified schedule for lungworm vaccination of calves. Vet Rec. 1984;114(2):29-32.

47. Coles GC, Jackson F, Pomroy WE, Prichard RK, von Samson-Himmelstjerna G, Silvestre A, Taylor MA, Vercruysse J. The detection of anthelmintic resistance in nematodes of veterinary importance. Vet Parasitol. 2006;136(3-4):167-85.

48. Lyndal-Murphy M, Swain AJ, Pepper PM. Methods to determine resistance to anthelmintics when continuing larval development occurs. Vet Parasitol. 2014;199(3-4):191-200.

49. das Neves JH, Carvalho N, Rinaldi L, Cringoli G, Amarante AF. Diagnosis of anthelmintic resistance in cattle in Brazil: a comparison of different methodologies. Vet Parasitol. 2014;206(3-4):216-26.

50. Leathwick DM, Miller CM. Efficacy of oral, injectable and pour-on formulations of moxidectin against gastrointestinal nematodes in cattle in New Zealand. Vet Parasitol. 2013:191(3-4):293-300.

51. Taylor MA. SCOPS and COWS-'worming it out of UK farmers'. Vet Parasitol. 2012:186(1-2):65-9.

52. Hodgkinson JE, Kaplan RM, Kenyon F, Morgan ER, Park AW, Paterson S, Babayan SA, Beesley NJ, Britton C, Chaudhry U, et al. Refugia and anthelmintic resistance: concepts and challenges. Int J Parasitol Drugs Drug Resist. 2019;10:51-7.

\section{Publisher's Note}

Springer Nature remains neutral with regard to jurisdictional claims in published maps and institutional affiliations. 